\title{
A!
}

This is an electronic reprint of the original article.

This reprint may differ from the original in pagination and typographic detail.

Pawlicka-Deger, Urszula

\section{Place matters}

Published in:

ARTS AND HUMANITIES IN HIGHER EDUCATION: AN INTERNATIONAL JOURNAL OF THEORY, RESEARCH AND PRACTICE

DOI:

$10.1177 / 1474022220961750$

Published: 28/09/2020

Document Version

Publisher's PDF, also known as Version of record

Published under the following license:

CC BY

Please cite the original version:

Pawlicka-Deger, U. (2020). Place matters: Thinking about spaces for humanities practices. ARTS AND

HUMANITIES IN HIGHER EDUCATION: AN INTERNATIONAL JOURNAL OF THEORY, RESEARCH AND

PRACTICE, 1-19. [1474022220961750]. https://doi.org/10.1177/1474022220961750

This material is protected by copyright and other intellectual property rights, and duplication or sale of all or part of any of the repository collections is not permitted, except that material may be duplicated by you for your research use or educational purposes in electronic or print form. You must obtain permission for any other use. Electronic or print copies may not be offered, whether for sale or otherwise to anyone who is not an authorised user. 


\section{Place matters: Thinking about spaces for humanities practices}

\author{
Urszula Pawlicka-Deger (D) \\ Department of Media, Aalto University, Espoo, Finland; \\ Institute of Advanced Studies, University of Birmingham, \\ Birmingham, UK
}

Arts and Humanities in Higher Education $0(0) \mathrm{I}-19$ (C) The Author(s) 2020 (c) (i)

Article reuse guidelines: sagepub.com/journals-permissions DOI: $10.1177 / 1474022220961750$ journals.sagepub.com/home/ahh

@SAGE

\begin{abstract}
This essay reflects on the role of place for humanities practices and contributes to emerging discussions on infrastructure for the humanities and socio-material conditions of scholarly knowledge production. I provide a theoretical framework for studying venues for humanities work drawing on the phenomenological approach to the concepts of place and space, the pedagogical perspective on learning spaces in higher education, and epistemological studies of scientific places. Next, I analyse the landscape for the reconfiguration of humanities venues and present arguments for engaging with space by referring to the functioning of digital humanities. This essay shows that place is an extremely important resource, seeing as it is endowed with the power to drive new practices, institutionalize a community, and consolidate a discipline. Therefore, humanists should reflect critically on the 'architecture of the humanities' and engage in making their own spaces that determine practices, communication, and well-being.
\end{abstract}

\title{
Keywords
}

Place and space, humanities space, architecture of the humanities, infrastructure, laboratory, situated knowledge production, community of practice, digital humanities

\section{Introduction}

From the 1980s onwards, science and technology studies and the history of science have turned their attention to spaces for experiments and the production of

\section{Corresponding author:}

Urszula Pawlicka-Deger, Department of Media, Aalto University, Espoo, Finland.

Email: pawlickadeger@gmail.com 
knowledge. All sites used for scientific inquiry have become objects of exploration in order to comprehend the interweaving of place and knowledge. With the publication of Laboratory Life by Bruno Latour and Steve Woolgar (1979), a laboratory, in particular, came to be considered as a gateway to understanding how scientific knowledge is constructed. Knorr Cetina (1981), Galison (1999a, 1999b), and Livingstone (2003), among others, sought to answer the following seminal questions: How does a space of inquiry determine the investigations carried out there? How is scientific knowledge created in a particular place? How do the buildings and sites entail specific practices and values and how do they shape the identities of researchers and fields?

While the study of scientific spaces is well-grounded, a discussion of the intertwining of place and humanities knowledge has been largely unexplored. We rarely think of the 'architecture of the humanities' in a manner similar to, in the words of Galison and Thompson, the 'architecture of science' (1999). Based upon common belief, humanistic research is not tied to a place; therefore, it might be conducted in an office, a library, a café, or at home. This broad range of workplaces results from humanities practices that are performed in isolation and do not require particular resources or facilities in comparison to scientific labs and their instruments. This common thinking and picture of humanistic work have not only been simplified but also significantly transformed. Even though humanities research is a result of individual work, it does take place in a particular space that is circumscribed by institutional, geographical, and socio-cultural factors. Questions thus arise as to how we condition knowledge production in the humanities and how we can use different venues to extend and enrich humanities work. The rise of laboratories and makerspaces in the humanities in recent years prompts us to rethink the role of place in this field and evaluate critically the conditions for knowledge production that we provide for researchers at our institutions.

This essay reflects on the role of space in humanistic work, builds a theoretical framework for studying a scholarly place, and analyses the landscape for the reconfiguration of humanities venues. I particularly refer to the field of digital humanities that emphasizes the significance of place in supporting new research practices, including computational experimentation and collaboration. The following questions help guide this paper: How are the humanities attached to a place? How can we study the connections between humanities venues (e.g., a library's reading room, office, workshop, lab, makerspace) and the knowledge produced there? How can we create the conditions necessary for new forms of scholarship to emerge through physical spaces? How can we reconfigure humanities spaces to support specific practices, build a community around them, and inspire collaboration? How do new spaces for humanities inquiry inform new values of scholarly work and transform research practices? How can grassroots initiatives play a transformative role in establishing a place of/for humanities on the university campus?

I begin by providing theoretical tools, including discourses on the notion of place and space from the epistemological and sociological perspectives, the design 
of learning spaces in higher education within a pedagogical context, and the history of space in scientific knowledge production as presented in science and technology studies and the history of science. Next, I review the emerging debate on space and infrastructure in the humanities. Afterwards, I examine the current institutional and spatial changes occurring in the humanities to show how the ongoing 'redesigning' and 'rebranding' of its places is a specific sign of the transformations of the field and how its identity is shaped through spaces. To this end, I refer to reports, scholarly discussions, and statements put out by humanities laboratories.

The perspective presented in this essay stems from the conviction that place matters for humanities research and teaching and yet its importance has remained largely unexplored by scholars, managers, and policymakers. I argue that we should reflect critically on venues used in scholarly knowledge production, interrogate what values are embedded in particular places, and engage in making our own spaces, spaces that determine researchers' practices, communication, engagement, and well-being.

\section{A theoretical framework: The discourse on place and space from an interdisciplinary perspective}

\section{The phenomenological approach to the concepts of place and space}

The first branch of theorizing on the notion of place involves the phenomenological, epistemological, and sociological approaches from the perspectives of geography and the history of ideas. Drawing on essential studies on place and space by Relph (1976), Agnew (1989, 2011), Lefebvre (1991), and Harrison and Dourish (1996), I define place as a socially constructed physical location that engages the aspects of structure, materiality, interaction, cultural representation, and social behaviour. 'In the simplest sense place refers to either a location somewhere or to the occupation of that location. The first sense is of having an address and the second is about living at that address' (Agnew, 2011: 318). In contrast to the specific notion of place, space is a more abstract concept that can be considered in nonphysical ways, including as geographical space or a digital platform. Therefore, as Harrison and Dourish argued, space is the opportunity to build a place framed as the understood reality (1996: 1).

Since I will identify different reconfigurations of space for humanities research and teaching, later on, it is important to understand how the concepts of place and space are entangled with social relations and knowledge production.

In his seminal work The Production of Space (1991), Lefebvre presented three ways of interweaving society with space. The first dimension is the 'spatial practices of a society', meaning that all daily practices and actions are situated in particular locations and embedded in specific spaces and times. In other words, the human experience is always anchored in a space that constitutes and conditions our work. The second interweaving involves 'representations of space', which 
means the conceptualized spaces envisioned by planners, scientists, and other experts that tend towards systems of verbal signs, including maps, models, and designs. The third manifestation of space in Lefebvre's triad is 'representational space', which is the lived space that is occupied by inhabitants and users (1991: 3839). As Boys explained in his engaging publication on the architecture of postcompulsory education, 'It is the space that is or can be altered by ordinary people; where their imaginations seek to appropriate, adapt or transform "normal" social and spatial arrangements and where change "from the bottom up" can occur, although often incoherent or partial' (2011: 80).

The political geographer Agnew (2011), identified three fundamental aspects of place. The first meaning is "place as a location or a site in space where an activity or object is located and which relates to other sites or locations because of interaction, movement and diffusion between them' (p. 326). To put it slightly differently, all places are featured by their locations and all objects are defined by spatial relations. The second aspect involves 'place as a series of locales or settings where everyday-life activities take place’ (p. 326). A locale in Agnew's definition consists of the material settings for social relations. It possesses a concrete form that involves everyday life and can be a workplace, home, shopping mall, church, and so on. A locale structures social interaction and communication as well as embeds concrete attitudes and behaviours. The third aspect is "place as sense of place or identification with a place as a unique community, landscape, and moral order' (p. 327). This last aspect involves the emotional attachment people have to place and the strong feelings of belonging to a place. This dimension of place is particularly significant when we reflect on spaces in the academy. Here, place is not simplified to a material setting but instead is an object that has the power to shape social relationships through the complex mechanisms of inclusion and exclusion.

Lefebvre and Agnew provide a rich theoretical matrix for understanding how society conceptualizes, produces, and perceives space. The sociology of space shows that the spatial dimension and its socio-material constitution play an integral part in human experience. The discourses on the spatial practices, place identity, the sense of place, place-making, and place attachment and exclusion are vital for a better comprehension of the role of place in social practices that include research, teaching, and learning in higher education. The discussion of physical place involves many aspects, such as architecture, design, organization, affiliation, policy, and equipment. The social practices are also located in a particular environment (local, regional, and national contexts), which affects their development and implementation. All these factors shape the conditions and possibilities for doing scholarly work. Hence, we can discern how the concepts of place and space are important for the debates of the situatedness of scholarly knowledge production.

\section{The pedagogical approach to learning spaces in higher education}

The discourse on place and space is well developed in terms of the studies of learning spaces in higher education, at least from the pedagogical and architectural 
perspectives, in studies by Savin-Baden (2008), Klein (2010), Boys (2011), and Friedman and Worden (2016). This section will review the most significant aspects of the discussion on the relationship between learning and space in terms of the further understanding of new sites for humanities practices.

According to Savin-Baden, learning spaces are 'places of engagement where often disconnected thoughts and ideas, that have been inchoate, begin to cohere as a result of the creation of some kind of suspension from daily life. In such spaces, staff often recognize that their perceptions of learning, teaching, knowledge and identity are being challenged and realize that they have to make a decision about their response to such challenges' (2008: 7). Further, she identifies common types of learning spaces that may include physical places, social learning spaces for dialogue and debate, and digital spaces for discussion with others. Learning spaces are thus considered and created via their spatial and temporal dimensions.

Drawing on the phenomenological approach to the concept of space presented in the previous section, space becomes a vital and necessary resource in the academy since it defines the organization of universities (e.g., division into disciplinary departments), provides specific locations for knowledge access and production (e.g., a library, laboratory, makerspace), creates an environment of opportunity for researching and learning (e.g., temporary spaces in the form of workshops and lectures), and conditions the way people meet, interact, and share ideas (e.g., through the design of common spaces, long corridors, interdisciplinary buildings). Given the vital role of space in higher education, it is thus essential to reflect on the design and organization of learning spaces. The discussion on learning spaces aims at a better understanding of how to make enhanced learning venues, developing tools and tactics for improving the architecture of post-compulsory education (Boys, 2011), and addressing the question of how interdisciplinary spaces should be designed to foster cross-disciplinary interactions (Friedman and Worden, 2016).

Interdisciplinary research and learning can be enhanced through space. As Friedman and Worden claim, 'Campus space is one resource which can be allocated to interdisciplinary endeavors to make them successful' (2016: 130). They point out three rationales in support of this argument. First, the organizational division of a university into faculties and departments is reflected in the spatial arrangement of the campus; therefore, space designs reinforce disciplinary boundaries. Hence, it becomes vital to "create a place on campus where scholars from different academic "homes" can convene to help facilitate cross-disciplinary interaction' (p. 130). Second, space plays a significant role in the development of the community that, in turn, is essential for research and teaching practices. Referring to Boix Mansilla and colleagues' analysis of interdisciplinary research teams, Friedman and Worden state that interdisciplinary groups 'depend not just on shared knowledge and methodologies, but the "human conditions" of collective purpose and solidarity' (p. 130). The community is thus the core of learning, teaching, and research practices, and it should be created and supported by spatial configurations. Third, space also constitutes a 'symbolic emblem of status and legitimacy, which is important to the establishment of new academic 
specializations' (p. 131). Thus, the allocation of a physical place is a gesture towards institutionalizing an enterprise and legitimizing its existence.

Space is a crucial facility that possesses the power to re-institutionalise and reconfigure a field within a university's organizational structure. Engagement in establishing new spaces is thus a strategic act since, as Boys stated, it involves changing the locations, relationships, scale and distinctiveness of practices; even if the resulting impacts are felt most at the small-scale and/or local level' (2011: 117). Taken together, the pedagogical approach to learning spaces shows how the design of space plays a significant role in social and spatial practices; how common places are significant in terms of fostering collaborative and interdisciplinary efforts; and how space is used for the establishment of new academic specializations. All these aspects will surface again in the discussion about creating spaces in the humanities field.

\section{The epistemological approach to scientific spaces}

To build the theoretical framework for studying venues for humanities practices, it is imperative to review the literature on the role of space in science. Scientific work occurs in many different places, such as a laboratory, an observatory, and the field. Theorists of science and technology studies and the history of science have studied the interrelations between space and knowledge creation since the 1980s. They have investigated the significance of physical locations in the shaping of scientific inquiries via an epistemological and sociological approach. Livingstone, the historian of geographical knowledge and the spatiality of scientific culture, challenged the common assumption that scientific claims are universal and detached from the place from which they emerged (2003). His seminal publication Putting Science in Its Place showed how scientific knowledge is situated and embodied in the surrounding environment. In the following section, I will briefly present the most important reflections of the social science researchers, who established laboratory studies within the science and technology studies.

In the 1970s, sociologist Bruno Latour stepped inside a neuroendocrinology research laboratory at the Salk Institute in California to seek answers to the questions: What happens inside laboratory walls? How are scientific facts produced in a laboratory? What is the theoretical power of the notion of a lab? (Latour, 1987; Latour and Woolgar, 1979). Questions such as these stimulated ethnographic studies of laboratories in the 1970s and 1980s aimed at understanding scientific work. Laboratory ethnography was a seminal movement that saw science as the social practice of constructing scientific knowledge rather than as an area that merely seeks to reveal reality. It gave rise to laboratory studies, that is, 'the study of science and technology through direct observation and discourse analysis at the root where knowledge is produced, in modern science typically the scientific laboratory' (Knorr Cetina, 1995: 140). The lab, a place equipped with specialized instruments and technologies for experimental studies, became a gateway for understanding how scientific knowledge is constructed. Theorists used 
a novel approach to the study of scientific knowledge production, that is, direct observation of scientists at work and participation in day-to-day work and meetings. Sociologists aimed to reveal the complexities of the following issues: the way of constructing scientific knowledge; the role of material objects and artefacts in the knowledge creation; the culture of laboratory work; and the function of scientific community.

While laboratory studies deal with disclosing the mechanism of knowledge production in laboratory settings, the history of science and geographical knowledge aims at revealing the influence of different places and geographical locations on scientific practices. Livingstone showed that scientific knowledge is situated and affected by a local milieu. Thus, science is always embedded in a socio-cultural environment that can foster or hinder research practice (2003). Further, Livingstone sought to analyse all the spaces of scientific inquiry, ranging from the laboratory to the botanical garden, to show how the site conditions the investigations carried out there. In line with this perspective, I will examine the significance of physical places for humanities practices, keeping in mind Livingstone's claim that "the "where?" of scientific activity matters a good deal' (p. 3).

Historians and philosophers of science have also sought to understand how the architectural organization of spaces affects how scientists communicate, interact, and conduct research and to examine the role of common spaces, called by Galison 'trading zone' (1999b), in facilitating cross-disciplinary interactions. Galison (1999a) argues that the design of places plays a vital role in creating the identity of the field and scientists and positioning the scientist in cultural space.

The work on the design and architecture of scientific activities provides a useful theoretical framework to comprehend how scientists representing different disciplines and epistemological backgrounds can communicate, collaborate, and negotiate different research perspectives and cultures. I will further utilize the aspect of establishing interdisciplinary interactions and collaborations through common spaces.

\section{Developing the discussion on humanities spaces}

Humanistic thoughts have grown in many different spaces, times, and configurations: humanities centres, libraries, seminars, and workshops. Since humanistic work occurs in particular places, why have scholars not been involved in the discussions concerning their own working conditions and the development of their research infrastructure?

The main reason for the lack of engagement is the long-lasting belief that the humanities have no infrastructure (Svensson, 2016). Although they utilize libraries, centres, software systems, publishing and distribution systems, the humanities have been reluctant to see themselves as engaging infrastructure. Svensson identified the following four arguments highlighting the complex relationship between the humanities and infrastructure. First, infrastructure is associated with the fields of science, technology, and engineering; hence, it is seen as an object in the 
sense of being located there and as an object of critical inquiry separate from the humanities' (p. 170). Second, the humanities have been unwilling to engage with their own modes of knowledge production critically, which has contributed to their reputation for having no infrastructure. Third, the humanities are pictured as constituting an 'institutionally underprivileged and threatened' field, 'which is not compatible with acknowledgment of existing infrastructure' (p. 170). The last argument stems from the assumption that the humanities lack 'the capacity to imagine and implement intellectually driven infrastructure' (p. 171). These four reasons show concisely why the notions of infrastructure and place are largely unexplored in the humanities and also why they should be taken up by researchers in a challenge to their own long-lasting image and organizational structure. The need for engaging with infrastructure was also pointed out in articles published in non-academic journals and advocated for building a laboratory for the humanities as a place fostering and propelling interactions, collaboration, and experiment (Davidson, 1999; Hiatt, 2005; Joselow, 2016).

Svensson's extensive work on the humanities infrastructure has provided an important voice in international discussions on approaching infrastructure from a critical perspective. He coined an intriguing concept of 'humanistic infrastructure' (2017) that constitutes a call for the interrogation of hidden layers of organizational structure in order to negotiate and reimagine better conditions for scholarly work. Svensson (2017) argues that 'infrastructure embeds ideas, values and institutional goals' and therefore we should consider those aspects when planning and creating new infrastructures.

Svensson (2016) examines the formation and the position of digital humanities among other disciplines and on the university campus and challenged the concept of infrastructure in this field. Drawing on Galison's concept of 'trading zones' to illuminate a path towards an understanding of how different epistemic traditions can work together productively, Svensson conceptualizes the digital humanities as specific 'trading zones' where people representing different disciplines gather together to share, collaborate, and provide inspiration (2016). The vision of digital humanities as a liminal space challenges, however, the institutional position of the field within the university. As he argues, 'One key question, in any case, is whether the digital humanities prefer a liminal position, or whether there is a push toward a more independent role and a more disciplinary, departmental structure' (p. 110). Therefore, there is a tension between a desire on the part of the digital humanities to be seen as a flexible field at the crossroads of many disciplines and an attempt to become a discipline with a sustainable, institutional place. To reconcile these efforts, Svensson proposed the notion of 'meeting place' (p. 115), seen as both a physical place with its own organizational status and a concept that implies the integration of disciplines and epistemological flexibility. The meeting place is a space that is both liminal and institutionalized.

In the vein of Svensson's research, Foka et al. (2018) reflect on the HUMlab, the humanities laboratory infrastructure to show how the material, social, and spatial components condition knowledge creation. Although the digital humanities field 
requires a robust digital infrastructure, it is affected strongly by an organizational and material space that influences the scholarly work. The authors exposed a digital humanities lab as a socio-material organization, based on their experience in developing the material infrastructure of HumlabX in relation to new technology investments. Their essay is a perfect example of what self-reflections on a space should look like and why we should remain open to the idea of redesigning our own spaces and engage in the development of digital research infrastructure policies.

Svensson advocated for the engagement in building infrastructure for the humanities as well as conceptualizing and critiquing such infrastructures. However, as he observed, engagement is still not a common practice among scholars who are not keen to reflect critically on their own physical and organizational structures (2016: 131).

There are a few contributions that constitute a reflection on the humanities infrastructure and place in the context of the academic organization (Fraistat, 2012; Maron and Pickle, 2014; Nowviskie, 2012), library spaces (Hartsell-Gundy et al., 2015; Kavanagh Webb, 2018; Wilson, 2020), and socio-material conditions (Foka et al., 2018; Pawlicka-Deger, 2020; Smithies, 2017; Svensson, 2018). In 2018, a group of scholars formed the Critical Infrastructure Studies initiative (CIStudies, n.d.), which aims to develop this nascent field that uses infrastructure as a critical lens for analysing socio-cultural concerns (Liu, 2018). This emerging field, at the intersection of science and technology studies, media studies, digital humanities, and infrastructure studies, is a promising move towards engaging the humanities in making their own infrastructure and developing a theoretical framework for investigating infrastructural influences on knowledge production. This is thus an exciting time for the humanities as its research areas are being expanded considerably by new inquiries at the intersection of critical studies and infrastructure studies.

\section{(Re)designing spaces for humanities practices}

In recent years, the landscape of humanities infrastructure and working places has changed with the development of the digital humanities, a young field that applies digital tools and methods to the humanities. Although the concept of digital comes with an assumption of dematerialization and detachment from a physical location, space still plays a significant role in conditioning digital humanities work. The field has come to require a research infrastructure as well new practices not yet common in the humanities, such as collaboration, hands-on work, and experiments. Even though scholars can argue that these practices are not as new as we think, so far, they have rarely described their work via these categories. The digital humanities promote a new mode of scholarship based on values of openness, collaboration, diversity, and experimentation (Spiro, 2012). Spiro rightly stated that the digital humanities community promotes an ethos that stresses collaboration as essential to its work and this aspect, in particular, contributes to the transformation of the humanities practices at large: 'Instead of working on a project alone, a digital 
humanist will typically participate as part of a team, learning from others and contributing to an ongoing dialogue' (2012).

The new practices require institutional support in terms of allocating and building a new space that would contribute to fostering digital scholarship, institutionalizing the field, and enhancing its visibility within a university's organizational structure. Since the field demands fluid boundaries between academic departments, the question is where and how to establish a venue for supporting such interdisciplinary and collaborative practices in the vein of Agnew's conceptualization of place as a location (physical site), series of locales (social activities), and sense of place (community attachment) (2011: 326-327). The resulting spaces have become a precious resource for promoting and propelling interdisciplinary, team-based, and technology-driven work.

Consequently, many organizational changes have occurred in the humanities field. The humanities have established various kinds of spaces so far associated with non-humanities disciplines, such as scientific laboratories with their wellestablished institutional model for experimental and instrument-intensive research, makerspaces with their engineering-related model for assembling and tinkering with things, and studios with their artistic model for producing objects. These new venues have been inspired by communal, unstructured hackerspaces, fab labs, and other sites of collaborative innovation emphasizing the experimental nature of their work, sharing knowledge, and a vibrant community built around them and focused on hands-on exploration. The new spaces have emerged in humanities departments, centres, and libraries all over the world, providing evidence of the changes taking place in scholarly research and teaching practices as well as becoming the driving forces behind their development. The architectural landscape of the humanities has been thus transformed to embrace the values that are promoted by the digital humanities and reflected in the very design of the spaces. A good example is Studio@Butler established at Columbia University in 2013. The studio aims to support emerging practices in pedagogy and digital scholarship and collaboration between scholars, educators, librarians, and technologists: 'Just as the leading academic libraries have always cultivated the solitary critical experience, they are increasingly beginning to support the social and collaborative research activity of groups and collectives' (Connelly et al., 2013). These values are thus embedded in the open, community-driven workspace at Butler Library.

The next observed change is related to reinstitutionalizing and renaming humanities units. Institutional transformations are never a neutral act; therefore, what fascinates me here is the way in which places are 'redesigned' and in some sense 'rebranded' and how these processes reflect changes in the field and direct its future development. For instance, the Reserve Book Reading Room, designed in 1931 for the Sterling Memorial Library at Yale University, was renovated and renamed the Franke Family Digital Humanities Laboratory in 2019, implying a shift from the so-called traditional humanities to the digital humanities. Great attention has been paid to the design of the space. The lab is divided into three 
sections: a flexible workspace enabling multiple layouts able to accommodate various events; an open-ceilinged glass cube for projects requiring high-powered computation and specialized gear; and individual workstations. The design of the place aims to support and enable collaborative and technology-based work. A library's reading room founded in 1931 was thus entirely redesigned to become a sign of digital changes in the humanities.

The second example is the Digital Humanities Institute (DHI) at the University of Sheffield, established in 1994 as HRI Digital and renamed the DHI in 2016. At the launch event held to celebrate the creation of the DHI, Tim Hitchcock, Professor of Digital History at the University of Sussex, gave a provocative talk devoted to the name change being seen as a 'dialogue between the past and the present' (2017). Renaming the place was suggestive and purposeful. After Hitchcock's talk, the DHI published a post giving the following three reasons for changing the name (Sheffield, 2017). First, HRI Digital was one of the UK's leading centres for digital humanities and played a significant role in the development of this field at the University of Sheffield; therefore, the new name recognizes all these accomplishments. Second, with the DHI acting as a separate unit, the HRI continues to exist as a larger institute with a broader mission. The last reason, yet listed as the second one, is the 'strategic shift' towards developing and promoting the digital humanities at Sheffield and beyond. As the DHI exemplifies, the change of name represents a strategic move in terms of mission and operation.

There are certainly more examples that come to mind: UCLA renamed the Center for Digital Humanities as Humanities Technology in 2018 as a way to provide technology expertise to the humanities, including but not exclusive to the digital humanities and the Maker Lab in the Humanities at the University of Victoria was rebranded as the Praxis Studio for Comparative Media Studies in 2019, which is seen as a step towards reframing the lab as not exclusively for the humanities but rather focused on media studies at large.

The presented institutional changes, running the gamut from designing to reframing spaces, show that the humanities are, to some degree, in a projection state. The field as a whole seeks to consolidate its position, enrich its practices, and interact with other disciplines. It currently is doing so through the use of space as a transformative agent. Next, I will present arguments for engaging in establishing spaces for scholarly practices and developing the critical discourse on humanities infrastructure.

\section{Fostering digital experimentation}

The field of digital humanities has given rise to a new mode of scholarship expressed via experiments and hands-on learning. Prescott (2016) aptly observed that: 'As humanities scholarship moves away from the production of scholarship in book or article form, so different administrative structures will be required' (p. 462). It is thus imperative to provide conditions and environment for the realization of these emerging practices in the humanities. The report of the American 
Council of Learned Societies considers the institutional requirements for advancing cyberinfrastructure that include providing training, sufficient resources, and learning spaces equipped with hardware, software, and digital tools. The report explicitly expresses the need for establishing laboratories as 'zones of experimentation and innovation for humanists' (ACLS, 2006: 36). As a result, labs have been launched in the humanities departments and libraries as unique places representing and promoting a culture of experimentation. This well-developed institutional model conditions the functioning of digital humanities and provides a locus for the burgeoning new forms of scholarship in the humanities at large. The Franke Family Digital Humanities Laboratory exemplifies an open learning space established in the Sterling Memorial Library of Yale University in 2015 and devoted to providing 'consultations, training, and opportunities that support Yale students, faculty, and cultural heritage professionals in their engagement with digital tools and techniques' (FFDHL, n.d.). The historic reading room located on the ground floor of the university's library was renovated into a high-tech laboratory equipped with dual-boot computers with specialized software for text, image, and spatial analysis. The design of the space aims to inspire the application of digital methods to humanistic questions and foster a collaborative work, as Catherine DeRose, the DHLab's manager stated, 'We want this space to facilitate serendipitous connections. (...) Maybe two scholars working here in different disciplines discover that they share a method in common and decide to begin collaborating' (Cummings, 2018). The design of the open and communal workspace reflects thus the guiding principles of the lab that encompasses such values as shared resource and support in digital humanities skills acquisition (FFDHL, n.d.). Located near the main entrance of the library and at the heart of the campus, the lab constitutes a welcoming and accessible space for everyone interested in incorporating digital tools to study the cultural data.

\section{Inspiring interdisciplinary collaboration}

The next argument for engaging with the discussion on a physical space for the humanities is related to enhancing interdisciplinary and collaborative practices. One barrier to interdisciplinary research and teaching lies in the spatial organization of the university's campus into schools and departments. Discipline-oriented cultures and structures can hinder interaction and collaboration across divergent branches of knowledge (TSPRU, 2016). Therefore, there is a need to allocate shared spaces on campus for scholars from different disciplines to meet and exchange ideas (Friedman and Worden, 2016). Interdisciplinarity, however, requires the collaborative work of researchers from different fields or institutions. This demands more institutional support in the form of providing infrastructure and networking opportunities for supporting the cross-disciplinary and teambased model of scholarship. As a result, the integration of different branches of knowledge has become the driving force behind building humanities laboratories seen as a 'meeting place' for people coming from different schools and 
departments. A good example is the Price Lab for Digital Humanities at the University of Pennsylvania founded in 2015 to support innovative uses of technology in the study of history, art, and culture, encourage development of new computing-intensive humanities courses, and promote collaborative facultystudent experiments and research projects. The lab is situated alongside the Wolf Humanities Center at the heart of the university campus. The central location supports its mission to serve as a "central node of communication and exchange across Penn's many departments, centers, and schools with expertise and interest in the digital humanities' (PLDH, n.d.). The space plays a networking role to coordinate and inspire a campus-wide partnership. The Price Lab's ethos expressed as 'Experiment-Collaborate-Innovate' is reflected in its physical situatedness and activities aimed to enable and nurture collaborative practices. In recent years, it has launched two project-based spin-off labs called DReAM Lab and Pop-Up Labs designed to enhance faculty and students' ability to use computational tools and improve their collaborative learning and research skills. Through such inspiring and innovative activities, the lab has become a central space for stimulating interdisciplinary cooperation thereby enriching and transforming the humanities practices.

\section{Building a sense of community}

'Scholars identify with their disciplines rather than with their departments', argues Friedlander (2008: vi) in pointing out the need for interdisciplinary 'third places' that would provide networking spaces. Faculty and researchers are affiliated with particular departments that are not necessarily aligned with their fields. Thus, there is a need for a 'home' for people who are scattered among schools and departments but connected with a common interest. Agnew's concept of 'sense of place' (2011) is particularly significant for the functioning of the interdisciplinary field of digital humanities that brings together a unique group of humanists, librarians, and software engineers. The community, in turn, is the core for developing and enhancing the position of the field at the university campus. The Scholars' Lab at the University of Virginia is a perfect example of a lab cultivating the value of community. The lab is described as a 'community lab for the practice of experimental scholarship in all disciplines, informed by digital humanities, spatial technologies, and cultural heritage approaches' (Scholars' Lab, n.d.). The lab, founded in 2006, is located on the fourth floor of Alderman Library and contains offices and graduate lounge, classrooms, workstations in the public space, and makerspace. The Scholars' Lab grew out of a grassroots initiative aimed to create an intellectual community in the digital humanities by lavishing attention and resources on graduate students and early-career scholars (Nowviskie, 2012). An initial experiment turned into a successful community-oriented lab where the value of community became part of the signature of the Scholars' Lab. The lab's motto is: 'We build up people and practices more than products', as they explain further, "People over projects" means that we care more about such outcomes, than about whether a 
formal “project” happens' (Scholars' Lab, n.d.). This important approach is often neglected by digital humanities places focused more on 'making things' rather than on building a strong and welcoming community. A physical place matters for providing facilities for experimentation with technologies like physical computing and augmented reality, but above all for building the sense of place attachment and belonging to a community. As it is exemplified by the Scholars' Lab: 'We've turned a large office into a Grad Fellows' lounge, full of bookshelves for their stuff. And we give our students a steady supply of caffeine and free run of our little staff kitchen. This means they not only have an intellectual home in the Scholars' Lab, they have a place that feels like home, and they see a good deal of us and of each other, no matter what academic department they come from' (Nowviskie, 2012).

\section{Enhancing the visibility of the humanities}

The last argument for advocating the development of venues for humanities practices is related to the aspect of visibility of the field. Having our own space makes a big difference in the way we are perceived by others. The same is true for any discipline which, in order to be legitimized and present, needs its own physical place on the campus map. Centres and laboratories, therefore, contribute to enhancing the visibility of the humanities on campus and beyond. Space also plays a key role in institutionalizing a discipline as it cements its place on campus. As Friedman and Worden argued, 'Existing discussions of campus space also frame it as a symbolic emblem of status and legitimacy, which is important to the establishment of new academic specializations' (2016: 131). Further, they recall Gieryn (2002), who claimed that: 'Laboratory buildings for chemistry or physics provide not just square footage for research and teaching; they convert the abstraction of "discipline" into something more palpable, stable, and enduring" (p. 46). The allocation of space has been significant for institutionalizing digital humanities and legitimizing its place within the university's organizational structure. Having said that, it is not that straightforward to secure space for digital humanities. Alexander and Frost Davis (2012) posed a significant and challenging question: 'Should liberal arts campuses engage with the digital humanities movement?'. The authors explore several serious arguments for disengagement in the field at small colleges and universities. The small institutional size, the uncertain definition of the digital humanities, and the lack of proper infrastructure, including allocating a physical place, are one of the main reasons why this new field is not present on every campus. To improve the development and visibility of digital humanities, small institutions engage with 'community building and on-campus advocacy and developing computing expertise and support for finding funding' (Alexander and Frost Davis, 2012). These kinds of grassroots initiatives function as networking nodes and advocates for the field that eventually becomes more and more visible on the campus. For instance, the Digital Scholarship Lab at the University of Richmond, established in 2007, represents a small physical unit and grassroots organization located in the university library and is devoted to 
developing innovative digital humanities projects that contribute to research and teaching at and beyond the university (DSL, n.d.). The values of teamwork and collaboration have become essential to the progress of the lab that also hires students to help perform some tasks, such as scanning documents and data entry (Wilson, 2020). The purpose of digital humanities places is not only to advance computationally-intensive research, but also to enhance the visibility of these new practices and consolidate the position of the field among other branches of knowledge. Once again, a physical place is used as a strategic way to strengthen the presence of the humanistic disciplines.

The reasons for engaging with space for humanities research and teaching vary according to local demands, commitments, and conditions. There are also different approaches for incorporating spatial changes on university campuses. Some transformations are planned and implemented as top-down directives resulting from national reports and policies. Other innovations result from the bottom-up approach and are particularly interesting to watch in terms of how they grow into sustainable and institutionally visible communities.

\section{Conclusion}

The phenomenological approach to the concepts of place and space, the pedagogical perspective on learning spaces in higher education, and epistemological studies of scientific venues demonstrate how the notion of place, along with the concepts of situatedness and design, plays a key role in conditioning knowledge production. These approaches provide useful theoretical tools for the study of venues for humanities practices. Despite the emerging discussion on spaces and infrastructure for the humanities, the topic of 'architecture of the humanities' remains largely underexplored. The ongoing spatial transformations in the field, however, prompt many questions that should be addressed by scholars in order to negotiate and improve the conditions for knowledge creation. How do the humanities manifest themselves through space? How does a place affect scholarly knowledge production? How can we reimagine socio-material infrastructure for the research and teaching of today and tomorrow?

Drawing on Galison's (1999a) claim that buildings are active agents in the transformation of scientific identity, how does the emergence of new spaces-laboratories and makerspaces - reconfigure the way we think about the humanities? First, it has been brought about a new perspective on the humanities in terms of their place within the socio-material system. By referring to Foka et al.'s (2018) reflections, we could see how the issue of place introduces new research inquiries, such as the impact of social and material assemblages on scholarly practices and knowledge creation.

Second, drawing on Livingstone's (2003) work, a discussion on the situatedness of scholarly knowledge can be opened. New venues can stimulate further research on the question of how humanistic knowledge is entangled with the institutional and socio-cultural environment (Oiva and Pawlicka-Deger, 2020). Third, 
laboratories and makerspaces enact new practices that transform the nature of scholarly work from solitary to collaborative, from writing texts to 'making things' (e.g., building digital collections), and from not being attached to a place to situated activities. It is thus interesting to observe how these practices, driven by these places, become desirable not only for the digital humanities with which they are associated but also in the humanities at large.

Space is an extremely important resource, seeing as it is endowed with the power to drive new practices, institutionalize a community, and consolidate a discipline. However, the conceptualization and building of a place entail many challenges not necessarily related to administrative bureaucracy. Any infrastructure embeds particular values; therefore, we need to reflect on them when planning and discussing new venues. While space plays a key role in conditioning knowledge production, there are many other factors, including community and culture that are as important as space. As Svensson rightly argues, 'The culture built around a place and institution plays a critical role. Also, a beautifully designed lab without people does not make much sense, and people can shape spaces to suit goals and visions even if the conditions are not optimal' (Svensson, 2016: 204). Designing spaces does not fall within a humanist's expertise but critical 'readings' of the infrastructures, policies, and conditions found in the humanities should certainly become part of critical inquiry. Given the observed spatial transformations, the time is ripe to think about the 'architecture of the humanities'.

\section{Acknowledgements}

I thank the Institute of Advanced Studies (IAS) at the University of Birmingham for awarding me the Vanguard Fellowship in Autumn 2019 and the Liberal Arts and Natural Science for hosting me. This essay was written as part of this fellowship and some results were presented during my lecture 'Place Matters: Exploring New Sites of the Humanities Practices' taking place at the IAS on 13 November 2019. I would like to thank the participants at the seminar for the feedback I received. I also thank two anonymous reviewers for their careful reading and many insightful comments and suggestions.

\section{Declaration of conflicting interests}

The author(s) declared no potential conflicts of interest with respect to the research, authorship, and/or publication of this article.

\section{Funding}

The author(s) received no financial support for the research, authorship, and/or publication of this article.

\section{ORCID iD}

Urszula Pawlicka-Deger (D) https://orcid.org/0000-0002-2626-4675 


\section{References}

ACLS (2006) Our cultural commonwealth. The Report of the American Council of Learned Societies Commission on Cyberinfrastructure for the Humanities and Social Sciences. New York: American Council of Learned Societies.

Agnew JA (1989) The devaluation of place in social science. In: Agnew J and Duncan J (eds) The Power of Place: Bringing Together Geographical and Sociological Imaginations. London: Unwin Hyman, pp.9-29.

Agnew JA (2011) Space and place. In: Agnew JA and Livingstone DN (eds) Geographical Knowledge. Thousand Oaks, CA: Sage, pp.316-330.

Alexander B and Frost Davis R (2012) Should liberal arts campuses do digital humanities? Process and products in the small college world. In: Gold MK (ed.) Debates in the Digital Humanities. Minneapolis: University of Minnesota Press, pp.368-389.

Boys J (2011) Towards Creative Learning Spaces Re-Thinking the Architecture of PostCompulsory Education. Abingdon, UK: Routledge.

CIStudies (n.d.) Critical infrastructure studies. Available at: https://cistudies.org/ (accessed 10 June 2020).

Connelly MJ, Dames NJ, and Tenen D (2013). Open letter in support of the digital humanities studio space at butler library. Columbia Academic Commons, 20 March. Available at: https://academiccommons.columbia.edu/doi/10.7916/D8J391XZ (accessed 14 April 2020).

Cummings M (2018) New home for Yale's Digital Humanities Lab opens in Sterling Library. Yale News, 4 October. Available at: https://news.yale.edu/2018/10/04/new-h ome-yales-digital-humanities-lab-opens-sterling-library (accessed 10 June 2020).

Davidson CN (1999) What if scholars in the humanities worked together, in a Lab? Chronicle Review, 28 May. Available at: www.chronicle.com/article/What-If-Scholarsin-the/24009 (accessed 10 June 2020).

DSL (n.d.) About the Digital Scholarship Lab. Digital Scholarship Lab, University of Richmond. Available at: http://dsl.richmond.edu/ (accessed 14 April 2020).

FFDHL (n.d.) Our mission. The Franke Family Digital Humanities Laboratory, Yale University Library. Available at: https://dhlab.yale.edu/about.html (accessed 10 June 2020).

Foka A, Misharina A, Arvidsson V, et al. (2018) Beyond humanities qua digital: Spatial and material development for digital research infrastructures in HumlabX. Digital Scholarship in the Humanities 33(2): 264-278.

Fraistat N (2012) The function of digital humanities centers at the present time. In: Gold MK (ed.) Debates in the Digital Humanities. Minneapolis: University of Minnesota Press, pp.181-191.

Friedlander A (2008) Foreword. In: Zorich D (ed.) A Survey of Digital Humanities Centers in the United States. Washington: Council on Library and Information Resources, Washington, pp.vi-vii.

Friedman JZ and Worden EA (2016) Creating interdisciplinary space on campus: Lessons from US area studies centers. Higher Education Research \& Development 35(1): 129-141.

Galison P (1999a) Buildings and the subject of science. In: Galison P and Thompson E (eds) The Architecture of Science. Cambridge: The MIT Press, pp.1-25.

Galison P (1999b) Trading zone: Coordinating action and belief. In: Biagioli M (ed.) The Science Studies Reader. New York: Routledge, pp.137-160.

Galison P and Thompson E (eds) (1999) The Architecture of Science. Cambridge: The MIT Press. 
Gieryn TF (2002) What buildings do. Theory and Society 31(1): 35-74.

Harrison S and Dourish P (1996) Re-place-ing space: The roles of space and place in collaborative systems. In: Proceedings of the ACM conference, Computer Supported Cooperative Work CSCW'96, pp.67-76. New York: ACM Press.

Hartsell-Gundy A, Braunstein L, and Golomb L (2015) Digital Humanities in the Library: Challenges and Opportunities for Subject Specialists. USA: American Library Association.

Hiatt G (2005) We need humanities labs. Inside higher Ed, 26 October. Available at: www. insidehighered.com/views/2005/10/26/we-need-humanities-labs (accessed 10 June 2020).

Hitchcock T (2017) Humanities2. Historyonics, 20 January. Available at: http://histor yonics.blogspot.com/2017/01/humanities-2.html (accessed 10 June 2020).

Joselow M (2016) Labs are for the humanities, too. Inside higher Ed, 12 July. Available at: www.insidehighered.com/news/2016/07/12/conference-explores-humanities-labs (accessed 10 June 2020).

Kavanagh Webb K (2018) Development of Creative Spaces in Academic Libraries: A Decision Maker's Guide. Cambridge, MA: Chandos Publishing.

Klein JT (2010) Creating Interdisciplinary Campus Cultures: A Model for Strength and Sustainability. San Francisco, CA: John Wiley \& Sons.

Knorr Cetina K (1981) The Manufacture of Knowledge. Oxford: Pergamon Press.

Knorr Cetina K (1995) Laboratory studies: the cultural approach to the study of science. In: Jasanoff S (ed.) Handbook of Science and Technology Studies. Los Angeles: Sage, pp.140-166.

Latour B (1987) Science in Action. How to Follow Scientists and Engineers through Society. Cambridge, MA: Harvard University Press.

Latour B and Woolgar S (1979) Laboratory Life: The Construction of Scientific Facts. Princeton: Princeton University Press.

Lefebvre H (1991) The Production of Space. Oxford and Cambridge, MA: Blackwell.

Liu A (2018) Toward critical infrastructure studies. NASSR, 21 April, 1-22.

Livingstone DN (2003) Putting Science in Its Place: Geographies of Scientific Knowledge. Chicago: Chicago University Press.

Maron NL and Pickle S (2014) Sustaining the digital humanities. Host institution support beyond the Start-Up phase. Ithaka S+R. Available at: https://doi.org/10.18665/sr.22548 (accessed 14 April 2020).

Nowviskie B (2012) Too small to fail. nowviskie.org, 13 October. Available at: http://now viskie.org/2012/too-small-to-fail/ (accessed 10 June 2020).

Oiva M and Pawlicka-Deger U (2020) Lab and Slack. Situated Research Practices in Digital Humanities - Introduction to the DHQ Special Issue. Digital Humanities Quarterly 14 (3). Available at: http://www.digitalhumanities.org/dhq/vol/14/3/000485/000485.html (accessed 15 September 2020).

Pawlicka-Deger U (2020) The laboratory turn: Exploring discourses, landscapes, and models of humanities labs. Digital Humanities Quarterly 14(3). Available at: http:// www.digitalhumanities.org/dhq/vol/14/3/000466/000466.html (accessed 15 September 2020).

PLDH (n.d.) What we do. Price Lab for Digital Humanities, University of Pennsylvania. Available at: https://pricelab.sas.upenn.edu/about/what-we-do (accessed 10 June 2020).

Prescott A (2016) Beyond the digital humanities center. The administrative landscapes of the digital humanities. In: Schreibman S, Siemens R and Unsworth J (eds) A New Companion to Digital Humanities. West Sussex: John Wiley \& Sons, pp.459-475.

Relph E (1976) Place and Placelessness. London: Pion. 
Savin-Baden M (2008) Learning Spaces: Creating Opportunities for Knowledge Creation in Academic Life. Maidenhead: Open University Press.

Scholars' Lab (n.d.) About Scholars' Lab. Scholars' Lab, University of Virginia Library. Available at: https://scholarslab.lib.virginia.edu/about/ (accessed 10 June 2020).

Sheffield (2017) The Digital Humanities Institute. Sheffield, 2 February. Available at: www.sh effield.ac.uk/faculty/arts-and-humanities/ahfnews/digital-humanities-institute-1.678034 (accessed 10 June 2020).

Smithies J (2017) The Digital Humanities and the Digital Modern. Basingstoke: Palgrave Macmillan.

Spiro L (2012) "This is why we fight”: Defining the values of the digital humanities. In: Gold MK (ed.) Debates in the Digital Humanities. Minneapolis: University of Minnesota Press, p.1634.

Svensson P (2016) Big Digital Humanities: Imagining a Meeting Place for the Humanities and the Digital. Ann Arbor: University of Michigan Press.

Svensson P (2017) Humanistic infrastructure keynote at the UCLA DH Infrastructure Symposium 2017. patriksv.net, 13 February. Available at: http://patriksv.net/humanis tic-infrastructure-keynote-at-the-ucla-dh-infrastructure-symposium-2017/ (accessed 10 June 2020).

Svensson P (2018) Contemporary and future spaces for media studies and digital humanities. In: Sayers J (ed.) Routledge Companion to Media Studies and Digital Humanities. New York: Routledge, pp.152-161.

TSPRU (2016) Landscape review of interdisciplinary research in the UK. Report to HEFCE and RCUK by Technopolis and the Science Policy Research Unit, University of Sussex, UK.

Wilson EA (2020) Digital Humanities for Librarians. Lanham, Maryland: Rowman \& Littlefield.

\section{Author biography}

Urszula Pawlicka-Deger held a postdoctoral researcher position in the Department of Media at Aalto University before joining King's Digital Lab at King's College London as a Marie Curie Fellow. Her research interests include the epistemology of a humanities laboratory, the process of knowledge production intertwined with technologies, and the infrastructural influences on humanistic work. Her last publications related to the concept of a laboratory include "Data, Collaboration, Laboratory: Bringing Concepts from Science into Humanities Practice" in English Studies (2017), “The Laboratory Turn: Exploring Discourses, Landscapes, and Models of Humanities Labs" in Digital Humanities Quarterly (2020), and the forthcoming article "Laboratory: A New Space in Digital Humanities" in Institutions, Infrastructures at the Interstices. Debates in the Digital Humanities (University of Minnesota Press). She is a Co-Editor of the DHQ special issue "Lab and Slack. Situated Research Practices in Digital Humanities" (2020, 14.3). 